\title{
CONSORCIO Y UNIÓN TEMPORAL: RASGOS DISTINTIVOS
}

\author{
Camilo E. Quiñones Avendaño \\ Doctorado en Derecho (en curso) Universidad Externado de Colombia; \\ Magíster en Derecho Económico, Universidad Externado de Colombia; \\ Especialista en Derecho Comercial, Universidad Autónoma \\ de Bucaramanga - Universidad Externado de Colombia. \\ Docente Universidad Autónoma de Bucaramanga \\ E: mail: camiloq2@gmail.com
}

\begin{abstract}
Resumen
Definir el tipo de organización para la ejecución de un proyecto reclama conocer los rasgos distintivos de las formas de organización empresarial, dentro de las cuales se encuentran Consorcio y Unión Temporal. En este documento se realiza una descripción de una y otra figura a partir del tratamiento legal en el derecho colombiano, sus rasgos distintivos, contenido y funcionamiento en la sociedad que permite tener una conceptualización clara, sobre esta nueva categoría jurídica.
\end{abstract}

\section{Palabras clave}

Consorcio, Unión temporal, Rasgos distintivos, Regulación.

\begin{abstract}
In order to define the organization type for the execution of a project, it is necessary to know about the distinctive features in the ways of managerial organization, inside which are Consortium and Temporary Union. This document presents a description of different figures starting from the legal treatment in the Colombian right, their distinctive features, content and operation in the society that allows to have a clear conceptualization, on this new legal category.
\end{abstract}

\section{Key Words}

Consortium, temporary union, distinctive features, regulation. 


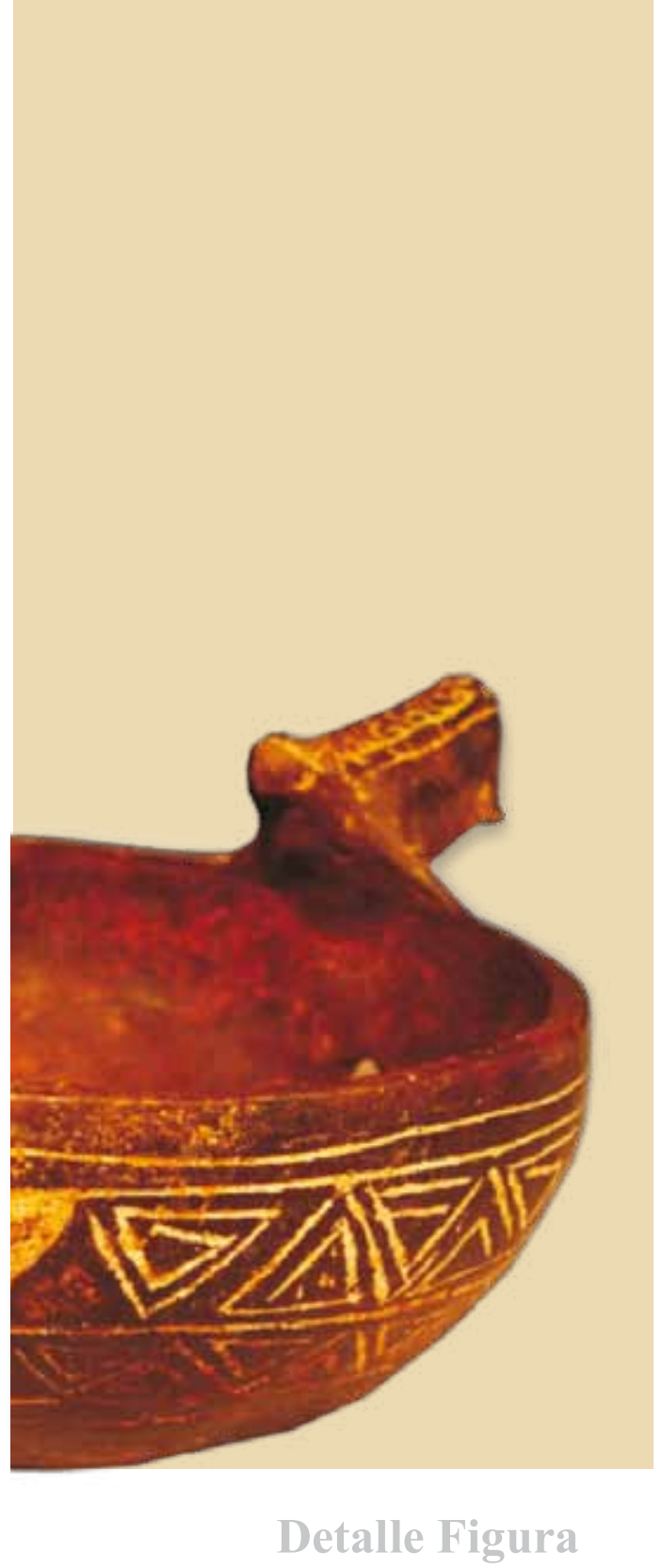

Cuenco Doble 


\section{CONSORCIO Y UNIÓN TEMPORAL: RASGOS DISTINTIVOS ${ }^{\circledR}$}

Camilo E. Quiñones Avendaño

\section{INTRODUCCIÓN}

El interés de los individuos por generar bienes y servicios en una economía, puede lograrse mediante una amplia gama de posibilidades: organización individual, ya bajo la forma de persona natural o de persona jurídica (empresa unipersonal ${ }^{1}$ y sociedad unipersonal ${ }^{2}$ ) y organización colectiva, de la cual forman parte un grupo de organizaciones con personalidad jurídica, que pueden adoptar la forma de asociaciones, fundaciones, cooperativas, organizaciones no gubernamentales o sociedades comerciales y otras sin personalidad jurídica, dentro de las que se encuentran la sociedad de hecho, las cuentas en participación, los consorcios y las uniones temporales.

En este escrito, bajo la perspectiva jurídica se quiere hacer un aporte a la evaluación de la forma de organización conocida en Colombia como Consorcio y Unión temporal, cuya regulación se halla contenida en el Art. 7 de la Ley 80 de 1993, de donde se extraen los rasgos distintivos básicos para su formación: integración, objeto y responsabilidades y en el Decreto 624 de 1989 (Estatuto Tributario), donde se les trata como sujeto pasivo de obligaciones tributarias.

* En el presente artículo de revisión, estudia la forma de organización Consorcio y Unión Temporal, en el marco del ordenamiento jurídico colombiano. Ley 80 de 1993.

$1 \quad$ Ley 222 de 1995 art. $71-81$.

2 Ley 1014 de 2006, art. 22; Decreto 4463 de 2006. 
Para tal fin, el escrito está dividido en tres partes. En la primera se presenta un marco referencial que consta de origen, concepto y marco legal vigente en Colombia, para luego, identificar los rasgos distintivos de la forma asociativa en la segunda parte $\mathrm{y}$, finalmente presentar algunas conclusiones en la tercera.

\section{MARCO REFERENCIAL}

En este apartado se pretende determinar el alcance del concepto de Consorcio, para lo cual se presenta el origen de la figura, su significado etimológico y gramatical y el alcance conceptual que le ha dado la doctrina jurídica, la jurisprudencia, la Superintendencia de Sociedades y la Dirección de Impuestos y Aduanas Nacionales (DIAN) y, finalmente se reseña el marco jurídico vigente en Colombia.

\section{Origen}

Es en el sector de transporte público colectivo, en la ciudad de Buenos Aires (Argentina), en el año de 1928, donde registramos el primer antecedente: Los propietarios de taxis ante la falta de trabajo, decidieron abandonar el sistema de oferta individual del servicio y empezaron, a ofrecer viajes en común o colectivos, a tarifa compartida, organizados en líneas de recorrido fijo. Se agruparon para producir unidos pero cada uno por su cuenta, con la posibilidad de apropiarse de lo que recaudaba.

El mecanismo de ingreso al consorcio, tenía como estímulo el que cada partícipe ingresaba, conservaba la propiedad de su vehículo, lo administraba y mantenía su individualidad, es decir, contaba con plena libertad para decidir y resolver todo aquello que guardara relación con su taxi. Elegían las rutas como mejor convenía a sus intereses y prestaban el servicio sin autorizaciones gubernamentales previas, lo que significa que identificaron una necesidad del mercado, se organizaron y crearon situaciones de hecho con fuerza suficiente para ser conocidos y utilizados.

La agrupación reclamaba identificar unos intereses comunes o de grupo, relacionados con un horario en la prestación del servicio, respeto de turnos, aprobación y utilización de un signo o símbolo que permitiera identificar la línea y contribuir con una cuota diaria para afrontar los gastos comunes.

La forma de ejercer esta actividad, nace sin reglamentos, sin contrato previo, con reglas de juego establecidas verbalmente, acordes con el servicio prestado, ausente de las formalidades propias de las sociedades comerciales que hoy conocemos, nace con una naturaleza eminentemente contractual, que no da nacimiento a una persona jurídica, sin límites ni restricciones entre propiedad y control, pero con carácter vinculante entre los miembros del consorcio (Aguerredondo, 1980).

El segundo antecedente es el "joint venture" o "Joint Adventure", expresiones utilizadas en Inglaterra y Estados Unidos, integradas por un verbo: to join, al que en nuestro idioma podemos entenderlo en distintas acepciones como unir, juntar, ligar, afiliarse, asociarse y por un sustantivo venture denota empresa, negocio, negocio 
arriesgado y adventure, que denota riesgo o aventura. Joint adventure, se utilizó en el imperio británico para designar a las corporaciones cuyo objeto estaba destinado a la colonización de nuevos territorios, los cuales estaban integrados por los gentlemen - adventures (caballeros aventureros), quienes realizaban aportes y al culminar la aventura repartían las ganancias obtenidas. Actualmente por joint venture entendemos una forma de contratación en virtud del cual “...dos o más personas o grupos de personas unen sus esfuerzos en torno a un proyecto determinado, de manera tal que asumen los riesgos que involucra el mismo y comparten los beneficios que se obtengan”. (Arrubla, 1998, 224).

\section{Concepto}

La expresión se deriva del latín Consortium, que puede entenderse como asociación, acción concertada de un grupo de personas que orientan sus esfuerzos a un mismo propósito. El Diccionario de la Real Academia Española ${ }^{3}$, presenta tres acepciones:

1. Participación y comunicación de una misma suerte con una o varias personas.

2. Unión o compañía de quienes viven juntos, principalmente los cónyuges y,

3. Agrupación de entidades para negocios importantes.

Desde el ámbito empresarial, consorcio y unión temporal son concebidas como una unión de esfuerzos, que se materializa con el aporte de parte de sus activos para formar una estructura empresarial nueva, donde las firmas colaborantes mantienen su existencia y autonomía en todos los negocios distintos a aquel que motivó la celebración del consorcio.

En sentido jurídico, consorcio y unión temporal son contratos. Uno y otro son contrato principal, contrato atípico, nominado, de formación consensual que vincula a los interesados en diseñar una estructura organizacional que les permita ejecutar determinada actividad de manera colectiva.

En la doctrina jurídica son definidos así:

“... es un instrumento que el ordenamiento jurídico ofrece a una pluralidad de sujetos para el desarrollo en común de cierta actividad, que consistiría en la realización de obras o en la prestación de determinados servicios, mediante la asociación de los sujetos interesados en tales resultados". (Stancanelli, 1972, 1229)

3 www.rae.es 
“...es un contrato de colaboración entre dos o más empresarios, con la finalidad de unir esfuerzos para lograr un determinado objetivo, generalmente, la construcción de una obra, la prestación de un servicio o en general la ejecución de una empresa determinada sin que se establezca una sociedad entre ellos". (Arrubla, 1998).

La Corte Constitucional colombiana en Sentencia C - 414 de Septiembre 22 de 1994. Magistrado Ponente: Antonio Barrera Carbonell, al determinar el alcance del concepto, expresó:

"El consorcio es una figura propia del derecho privado, utilizado ordinariamente como un instrumento de cooperación entre empresas, cuando requieren asumir una tarea económica particularmente importante, que les permita distribuirse de algún modo los riesgos que pueda implicar la actividad que se acomete, aunar recursos financieros y tecnológicos, y mejorar la disponibilidad de equipos, según el caso, pero conservando los consorciados su independencia jurídica".

La Corte Suprema de Justicia, en Sentencia de Septiembre 13 de 2006. Magistrado Ponente: Jaime Alberto Arrubla Paucar, señala que el consorcio:

“....en la práctica es el instrumento de cooperación del cual se sirven personas con actividades afines, que temporalmente y sin el ánimo de asociarse resuelven conjuntar esfuerzos para ejecutar determinado negocio, sin que se interfiera su organización jurídica o económica, en el derecho privado patrio no han sido objeto de regulación, constituyendo por ende una modalidad atípica de los denominados por la doctrina, contratos de colaboración, por el cual dos o más personas convienen en aunar esfuerzos con un determinado objetivo, consistente por lo general en la construcción de una obra o en la prestación de un servicio, sin que se establezca una sociedad entre ellos, puesto que no se dan los elementos esenciales del contrato de sociedad, amén de conservar cada cual su personalidad y capacidad para ejecutar las actividades distintas del negocio común”.

El Consejo de Estado, en Auto de Marzo 30 de 2006. Consejero ponente: Alier Eduardo Hernández Enríquez, define al consorcio como:

“... un convenio de asociación, o mejor, un sistema de mediación que permite a sus miembros organizarse mancomunadamente para la celebración y ejecución de un contrato con el Estado, sin que por ello pierdan su individualidad jurídica, pero asumiendo un grado de responsabilidad solidaria en el cumplimiento de las obligaciones contractuales". 
La Superintendencia en Concepto 220 - 45384, Julio 11 de 2003, ha definido los consorcios así:

“... es una figura en virtud de la cual varias personas naturales o jurídicas, unen sus esfuerzos, conocimientos, capacidad técnica y científica para la gestión de intereses comunes o recíprocos, y aunque parte de una base asociativa, no hay socios propiamente dichos sino un modelo de colaboración para la ejecución de uno o varios proyectos, pero cada uno de los asociados conserva su independencia, y, asumiendo un grado de responsabilidad solidaria en el cumplimiento de las obligaciones contractuales".

La Dirección de Impuestos y Aduanas Nacionales DIAN, en Conceptos 024187 Abril 28 de 2005 y 013765 del 9 de Marzo de 2004, ha expresado que:

"El consorcio y la unión temporal son figuras propias del derecho privado, utilizadas ordinariamente como un instrumento de cooperación entre empresas de personas naturales o jurídicas, cuando requieren asumir una tarea económica particularmente importante, que les permite distribuirse de algún modo los riesgos que pueda implicar la actividad que se acomete, aunar recursos financieros y tecnológicos, y mejorar la disponibilidad de equipos según el caso, pero conservando los consorciados su independencia jurídica".

Concepto tributario 013765 de $09 / 03 / 2004$.

“... es un convenio de asociación, o mejor, un sistema de mediación que permite a sus miembros organizarse mancomunadamente para la celebración y ejecución de un contrato con el Estado, sin que por ello pierdan su individualidad jurídica, pero asumiendo un grado de responsabilidad solidaria en el cumplimiento de las obligaciones contractuales".

\section{Marco Legal}

Las disposiciones legales que constituyen el marco jurídico de los consorcios y uniones temporales, son la Ley 80 de 1993 (Estatuto general de contratación pública), el Decreto 624 de 1989 (Estatuto tributario), el Decreto 856 de 1994 y la orden administrativa de la Dirección de Impuestos y Aduanas Nacionales (DIAN) 00001 de 2005. El objeto de regulación se presenta al detalle a continuación:

Ley 80 de 1993:

1. Permite a las entidades estatales celebrar contratos con consorcios y uniones temporales (Art. 6). 
2. Señala que hay consorcio: "cuando dos o más personas en forma conjunta presentan una misma propuesta para la adjudicación, celebración y ejecución de un contrato, respondiendo solidariamente de todas y cada una de las obligaciones derivadas de la propuesta y del contrato. En consecuencia, las actuaciones, hechos y omisiones que se presenten en desarrollo de la propuesta y del contrato, afectarán a todos los miembros que lo conforman". Art. 7.

3. Respecto a uniones temporales señala que se presenta "cuando dos o más personas en forma conjunta presentan una misma propuesta para la adjudicación, celebración y ejecución de un contrato, respondiendo solidariamente por el cumplimiento total de la propuesta y del objeto contratado, pero las sanciones por el incumplimiento de las obligaciones derivadas de la propuesta y del contrato se impondrán de acuerdo con la participación en la ejecución de cada uno de los miembros de la unión temporal". Art. 7.

4. Impone a los proponentes en una contratación los siguientes deberes. Art. 7: Indicar si su participación adopta la modalidad de consorcio o unión temporal; No modificar los términos del acuerdo celebrado entre los miembros del consorcio o unión temporal sin el consentimiento de la entidad pública contratante; Designar la persona que, para todos los efectos, representará al consorcio o unión temporal; Señalar las reglas básicas que regulen las relaciones entre ellos y su responsabilidad; Permite aplicar a las sociedades constituidas bajo cualquiera de las modalidades previstas en la ley, con el único objeto de presentar una propuesta, celebrar y ejecutar un contrato estatal, las disposiciones previstas en esta ley para los consorcios respecto a responsabilidad y efectos. Parágrafo 3. Art. 7.

5. Impone que de presentarse una inhabilidad o incompatibilidad sobreviniente a uno de los miembros de un consorcio o unión temporal, éste cederá su participación a un tercero previa, autorización escrita de la entidad contratante y advierte que en ningún caso podrá haber cesión del contrato entre quienes integran el consorcio o unión temporal. Art. 9

6. Los consorcios y uniones temporales responderán por las acciones y omisiones de sus integrantes. Art. 52

\section{Decreto 624 de 1989:}

Esta disposición es conocida como Estatuto Tributario Colombiano. En ella el tratamiento de los consorcios se dispone en: 
1. Impone el deber de inscribirse en el Registro Único Tributario ${ }^{4}$, no obstante que no son contribuyentes del Impuesto a la renta (Art. 18 modificado por Ley 223 de 1995). Los miembros del consorcio o la unión temporal deben llevar en su contabilidad y declarar de manera independiente, los ingresos, costos y deducciones que les correspondan, de acuerdo con su participación en los ingresos, costos y deducciones del Consorcio o Unión Temporal.

2. Atribuye responsabilidades relacionadas con retención en la fuente e impuesto a las ventas: a) Impuesto a la renta: No son contribuyentes del Impuesto sobre la Renta Retención en la Fuente. Son agentes de retención. (Art. 368 modificado por Ley 448 de 1998). b) Impuesto sobre las ventas: Son responsables de este impuesto, en el Régimen Común cuando en forma directa sean ellos quienes realicen actividades gravadas. (Art. 437 literal f).

\section{Decreto 856 de 1994}

Mediante esta disposición legal se reglamentó el funcionamiento del registro de proponentes en las Cámaras de Comercio. Se dispuso la obligatoriedad a cada uno de los miembros o partícipes de la unión temporal o consorcio, de estar inscritos, clasificados y calificados en el registro de proponentes ${ }^{5}$.

\section{Orden Administrativa DIAN 00001 de 2005}

Requisitos para la formalización del RUT de Consorcios: a) Presentación del documento privado donde conste la conformación del consorcio o la unión temporal, el que debe contener por lo menos: nombre del consorcio o de la unión temporal, domicilio consorcial, representante legal y el objeto del consorcio; b) Certificado de existencia y representación legal vigente de cada una de las sociedades o certificado de registro mercantil para personas naturales que conformen el consorcio o la unión

4 El Registro Único Tributario, RUT, es el mecanismo único para identificar, ubicar y clasificar las personas y entidades que tengan la calidad de contribuyentes declarantes del impuesto sobre la renta y no contribuyentes declarantes de ingresos y patrimonio; los responsables del régimen común y los pertenecientes al régimen simplificado; los agentes retenedores; los importadores, exportadores y demás usuarios aduaneros y los demás sujetos de obligaciones administradas por la Dirección de Impuestos y Aduanas Nacionales, respecto de los cuales se requiera su inscripción. (Art 555-2 del E.T).

5 El Registro de Proponentes tiene por objeto la inscripción, la clasificación y la calificación de todas las personas naturales o jurídicas que aspiren a celebrar con las entidades estatales los contratos señalados en el Art. 22 de la Ley 80 de 1993. Es administrado por las Cámaras de Comercio y la información que en ellos reposa es pública, es decir, puede ser consultada por cualquier persona. 
temporal, expedido por la Cámara de Comercio o entidad competente; c) Fotocopia del documento de identificación del representante legal del consorcio o unión temporal.

\section{RASGOS DISTINTIVOS}

El marco referencial permite caracterizar al Consorcio y Unión temporal, a partir de elementos que en el ámbito empresarial son considerados como parámetros de definición de la forma de organización necesaria para formular y ejecutar un proyecto. Los elementos tomados por el autor de este escrito son: naturaleza, sujetos, objeto, forma, contenido y capacidad:

\section{Naturaleza}

La descripción legal tanto de consorcio como unión temporal contenida en el Art. 7 de la Ley 80 de 1993, no le atribuye el carácter de persona jurídica, por lo que se reconoce en una y otra forma de organización, un carácter eminentemente contractual, específicamente un contrato de colaboración empresarial entre dos o más sujetos de derecho, que voluntariamente han decidido unir esfuerzos para lograr un objetivo sin que se establezca entre ellos sociedad.

Su celebración es jurídicamente viable tanto en el ámbito del derecho público como en el derecho privado. Esto significa, que es incorrecto afirmar que sea una figura exclusiva del derecho público, específicamente de la contratación estatal. Lo que se reconoce es que su incorporación al derecho colombiano se realizó desde esta disciplina.

No le reconoce el derecho colombiano, el atributo de la personalidad jurídica, lo que significa que celebrado el contrato de consorcio o de unión temporal, los derechos y obligaciones que surjan en la ejecución del acuerdo consorcial estarán en cabeza de todos y cada uno de los miembros de la colaboración.

El Art. 6 de la ley 80 de 1993, respecto a la responsabilidad de los miembros del consorcio o unión temporal señala que responden "....solidariamente de todas y cada una de las obligaciones derivadas de la propuesta y del contrato". Se trata de una responsabilidad solidaria o in solidum ${ }^{6}$, que emana de la ley y como mandato imperativo es irrenunciable e inmodificable por voluntad de quienes suscriben el contrato de colaboración empresarial. Esta solidaridad implica que: a) Todos los miembros del consorcio o unión temporal responden por la totalidad de las obligaciones contraídas en ejecución del contrato de colaboración, independientemente de la naturaleza y grado de participación en la colaboración; b) El patrimonio de cada uno de los miembros del consorcio o unión temporal es

6 Art. 1568 Código Civil. 
prenda general de los acreedores con quienes se obtenga vinculación en ejecución del contrato de colaboración empresarial; c) Quien contrate con un consorcio o unión temporal puede exigir la totalidad del cumplimiento de la obligación a cualquiera de los miembros del consorcio, sin que éstos puedan invocar a su favor el beneficio de división ni de excusión ${ }^{7}$; d) El cumplimiento de la prestación que se debe hecha por uno de éstos, extingue la obligación respecto a los demás; e) La constitución en mora de uno de los deudores solidarios acarrea igual situación para los demás; f) Si uno de los miembros del contrato de colaboración empresarial cumple por cualquiera de los medios equivalentes al pago, con las obligaciones contraídas en ejecución del consorcio o unión temporal, queda subrogado ${ }^{8}$ en la acción del contratante, con todos los privilegios y seguridades, pero limitada respecto de cada uno de los codeudores a la parte o cuota que tenga este codeudor en la deuda.

\section{Sujetos}

Respecto a los sujetos consorciados o miembros de la unión temporal, ha de señalarse que el marco jurídico vigente reclama dos o más personas sin calificación alguna, puede estar integrado sólo por personas naturales, sólo por personas jurídicas, por unas y otras, de derecho público o privado, con o sin ánimo de lucro, que han decidido unir esfuerzos (capital, trabajo, conocimiento, experiencia) para emprender un proyecto que de ejercerse individualmente no tendría la potencialidad de producir el mismo resultado.

Las condiciones de orden personal, financiero y capacidad técnica para unir esfuerzos en torno a un proyecto, no son impuestas por la regulación vigente. Son evaluadas por los miembros del consorcio o unión temporal, no sólo en función de su interés por generar bienes y servicios en una economía o por obtener lucro. Incide la capacidad técnica necesaria para presentar la propuesta, obtener la adjudicación y ejecutar el contrato que le sea adjudicado.

No hay en consorcios y unión temporal socios propiamente dichos, hay un modelo de colaboración para la ejecución de uno o varios proyectos, pero cada uno conserva su independencia y asume un grado de responsabilidad solidaria en el cumplimiento de las obligaciones contractuales.

$7 \quad$ En virtud del beneficio de excusión (Art. 2383 Código Civil) el fiador reconvenido puede exigir que antes de proceder contra él se persiga la deuda en los bienes del deudor principal y en las hipotecas o prenda prestadas por esta para la seguridad de la misma deuda

8 Conforme al Art. 1666 del Código Civil, la subrogación es la transmisión de los derechos del acreedor a un tercero, que le paga. 


\section{Objeto}

Dada la naturaleza contractual del consorcio y unión temporal, se reconoce que el acuerdo suscrito entre sus miembros, está amparado por la previsión legal contenida en el Art. 1517 del Código Civil, esto es, debe tener por objeto una o más cosas, que se trata de dar o hacer.

Quienes suscriben el contrato de colaboración, unen esfuerzos, con la única restricción legal denominada "licitud de objeto". Por tanto, pueden dar dinero, bienes apreciables en dinero (muebles o inmuebles) o comprometerse a un hacer para fortalecer la unión temporal o el consorcio. El hacer puede estar relacionado con labores de dirección, asesoría, operativas, ejecutivas o de cualquier índole, previamente concertadas y valoradas con quienes han decidido unir esfuerzos con un propósito común.

Dado el carácter contractual de una y otra figura, la obligación de dar no genera como consecuencia una transferencia del derecho real de dominio a favor del consorcio o unión temporal, sólo se trata de una entrega material, de una entrega de bienes afectada al cumplimiento de unos deberes fijados en el contrato.

El objeto puede llevarse a cabo tanto en el ámbito del derecho público, como en el derecho privado, “...según se presente la integración de los empresarios para contratar con entes públicos o empresas privadas", (Arrubla, 1958, 251). Conforme a la regulación prevista en el Art. 7 de la Ley 80 de 1993, el objeto lo constituye la presentación de una propuesta para la adjudicación, celebración o ejecución de un contrato. No obstante, al reconocer que su campo de acción también es el del derecho privado, el objeto lo constituye el trazado por los interesados que han decidido unir esfuerzos sin que entre ellos exista sociedad.

En uno y otro caso, el objeto debe ser lícito, esto es, que su contenido no viole intereses públicos o lo que es igual que no adolezca de ilicitud de objeto, “...expresión con la cual se designa el evento vicioso en que se conculcan aquellas disposiciones encaminadas, a lograr que los particulares, al crear sus negocios, atiendan también los intereses generales de la comunidad”. (Bohórquez, 1998, 115)

\section{Forma}

El marco jurídico vigente, no hace un señalamiento expreso respecto a la forma que deba adoptar el perfeccionamiento del contrato de colaboración empresarial que se denomine Consorcio o Unión Temporal, por lo que se considera como un negocio de forma libre o consensual.

Sin embargo, se advierte que la unión de esfuerzos que constituye el centro de una y otra figura, trasciende a otro extremo interesado en contratar con un grupo de sujetos que ofrezcan la potencialidad de ejecutar una obra, cumplir una labor o prestar un servicio. Esta circunstancia, reclama la necesidad de hacer constar en 
documento escrito las bases del acuerdo consorcial o de la unión temporal, de otra forma, los sujetos celebrantes estarían desprovistos de medio de prueba ante terceros de su intención de generar bienes y servicios al hacer uso del derecho de asociación.

\section{Contenido}

El marco de referencia de este estudio, muestra que la regulación colombiana sólo menciona esta figura como un instrumento en el campo de la contratación estatal, pero no señala cuál es el contenido mínimo, por ello, a la luz de la teoría del negocio jurídico puede afirmarse que se trata de un negocio nominado y atípico.

No obstante, el contrato de colaboración empresarial se rige por la norma general del derecho civil, en virtud de la cual todo contrato legalmente celebrado es una ley para los contratantes y no puede ser invalidado sino por su consentimiento mutuo o por causas legales (Art. 1602 Código Civil). Se recomienda a los sujetos celebrantes consignar en un escrito las reglas básicas que regulen las relaciones entre ellos, que comprendan como mínimo los siguientes elementos ${ }^{9}$ : Identificación de los sujetos celebrantes; señalar si la colaboración entre ellos adopta la modalidad de consorcio o unión temporal; objeto del consorcio o de la unión temporal, esto es, la razón de ser de la colaboración empresarial; señalar los derechos y obligaciones de cada una de las partes; señalar el término de duración o fijar las bases para determinarlo; Indicar quien será el representante convencional de los consorciados o miembros de la unión temporal; la forma como cada uno de los consorciados o miembros de la unión temporal contribuyen con la integración del consorcio; la estimación en porcentaje de la participación de cada uno de los consorciados o miembros de la unión temporal; lugar, época y forma en que se distribuirán los rendimientos derivados del desarrollo de la actividad que constituye el objeto del consorcio; mayorías para deliberar y para decidir en asuntos relacionados con el consorcio; forma y mayorías en que adoptarán las decisiones relacionadas con el consorcio; estimación anticipada de los perjuicios que en caso de incumplimiento de uno o alguno de los miembros deben pagarse a los miembros cumplidos o en su defecto la forma de liquidarlos; causales de terminación del consorcio o unión temporal; forma y oportunidad de liquidar definitivamente los negocios derivados del consorcio o unión temporal.

9 Se aclara que el listado no está previsto en la regulación como elementos esenciales, son recomendaciones hechas por el autor de este escrito bajo el entendido que no pueden estandarizarse los contratos de colaboración empresarial, por cuanto los niveles de previsión contractual cambian según la obra o contrato que se va a ejecutar o celebrar una vez perfeccionado el consorcio o unión temporal 


\section{Capacidad}

La capacidad para celebrar contratos se predica en forma directa y propia de las personas legalmente capaces, esto es, de las naturales y jurídicas. Es la aptitud que se tiene para ser sujeto de relaciones jurídicas, es decir, para realizar sin el ministerio de otra persona, actos con efectos válidos en la esfera del Derecho.

El Estatuto de Contratación Administrativa reconoce a los consorcios y a las uniones temporales capacidad para contratar junto con las personas naturales y jurídicas, pero se les permite que actúen como sociedades, esto es, a través de un representante convencional que se designe en el documento que da nacimiento, a una u otra forma asociativa. El Art. 6 de la Ley 80 de 1993, dispone que "pueden celebrar contratos con las entidades estatales las personas consideradas legalmente capaces en las disposiciones vigentes", y añade que "también podrán celebrar contratos con las entidades estatales, los consorcios y uniones temporales", disposición que invita a pensar que a pesar de no gozar de personalidad, excepcionalmente se les atribuye capacidad para contratar y obligarse con el Estado, a la postre no va más allá de autorizar la vinculación contractual de las entidades públicas, con las personas naturales o jurídicas que acudan a tales fórmulas convencionales -consorcio o unión temporal- con el fin de contratar con la administración, mediante la presentación de una sola propuesta en la que conjuguen potencial, experiencia y recursos, entre otros. ${ }^{10}$

Otro es el enfoque que se da para efectos procesales en lo atinente a capacidad. La carencia de personalidad jurídica, permite afirmar que no pueden demandar directamente ni ser demandados, a menos que se haga por intermedio de las personas que de manera independiente lo integran. Si un consorcio o unión temporal se ve obligado a comparecer a un proceso como demandante o demandado, cada uno de los integrantes del mismo debe comparecer en forma individual al proceso ya que carece de personería jurídica, a menos que dentro de las previsiones que se hubieren acordado al momento de constituir el consorcio se hubiere facultado a su representante para iniciar las acciones pertinentes, acciones que podrá promover en nombre de sus representados, que no son otros que los miembros del consorcio o de la unión temporal.

10 Sentencia - Septiembre 13 de 2006. Corte Suprema de Justicia. Sala de casación civil. Magistrado Ponente: Jaime Alberto Arrubla Paucar. Referencia: Expediente No. 88001-31-03-002-2002-0027101 


\section{CONCLUSIONES}

1. Consorcios y uniones temporales comparten las siguientes características:

1.1. Son modalidades de asociación, que no implican el nacimiento de una persona jurídica.

1.2. Son contratos de colaboración atípicos, por lo que se reclama en su celebración anticiparse a eventuales conflictos que puedan presentarse entre sus miembros e insertar las cláusulas necesarias para reducir la complejidad que puede surgir en su funcionamiento y extinción.

1.3. No constituyen una asociación como las conocidas por el derecho privado, ni una sociedad mercantil, sino que hoy se perfilan como una nueva categoría jurídica, como un modelo de colaboración en el campo del Derecho Público y del Derecho Privado, para promover y ejecutar obras y servicios de interés general o particular.

1.4. Su formación no requiere la formalidad de Escritura Pública lo que evidencia flexibilidad en los trámites a realizar para el perfeccionamiento de este contrato.

1.5. En él no hay socios propiamente dichos, su finalidad es la unión de esfuerzos de colaboración, para prestar el servicio o para ejecutar una labor, para su existencia no es requisito esencial la presencia de la intención de participar en el reparto de utilidades como se exige para las sociedades comerciales.

1.6. Unión de esfuerzos y capitales que permite obtener mejores y mayores resultados, de los que pudieran lograrse con la simple actividad individual.

1.7. Dos o más personas se reúnen para actuar unidas bajo una misma dirección y reglas comunes, aunque conservan su personalidad e independencia jurídica.

1.8. Como contratos de colaboración empresarial, no están sometidas a registro mercantil en Cámara de Comercio como comerciantes, los deberes comerciales los cumple de $m$ anera independiente cada uno de sus miembros en la medida en que ostente la calidad de comerciante. La regulación sólo obliga a la inscripción, clasificación y calificación de los mismos en el registro de proponentes.

1.9. No son sujetos de derecho, pero el Estatuto Tributario les impone deberes relacionados con la inscripción en el Registro Único Tributario e impuesto a las ventas, es decir, los trata como sujetos de derecho.

2. En la unión temporal, la responsabilidad es solidaria entre sus miembros frente a las obligaciones que surgen de la propuesta y del contrato, pero tratándose de sanciones por incumplimiento de las obligaciones, éstas se imponen de acuerdo con la participación en la ejecución de cada uno de los miembros de la unión temporal. Es este el único rasgo distintivo con el Consorcio. 


\section{REFERENCIAS}

Aguerredondo, G. (1980). La empresa consorcio. Abeledo-Perrot. Buenos Aires. Arrubla. J. (1998). Contratos Mercantiles. Tomo II. Biblioteca Jurídica Diké, $3^{\mathrm{a}}$ Edición, Bogotá.

Bohórquez, A. (1998). De los Negocios Jurídicos en el Derecho Privado Colombiano. Volumen 1, Editorial UNAB, Segunda Edición.

Stancanelli, G. (1972). Los consorcios en el Derecho Administrativo. Traducción del Italiano, Madrid.

\section{Legislación}

Ley 80 de 1993

Decreto 624 de 1989

Decreto 856 de 1994

Código Civil Colombiano

\section{Jurisprudencia}

Consejo de Estado

Auto de Marzo 30 de 2006. Consejero ponente: Alier Eduardo Hernández Enríquez

Corte Constitucional.

Sentencia C 414 de Septiembre 22 de 1994. Magistrado Ponente: Antonio Barrera Carbonell.

Corte Suprema de Justicia

Sentencia - Septiembre 13 de 2006. Sala de casación civil. Magistrado Ponente: Jaime Alberto Arrubla Paucar. Referencia: Expediente No. 88001-31-03-002-200200271-01.

\section{Conceptos Entes Administrativos}

Dirección de Impuestos y Aduanas Nacionales: 013765 del 9 de Marzo de 2004; 024187 del 28 de Abril de 2005

Superintendencia de Sociedades: 220 - 45384, Julio 11 de 2003 